\title{
The Effect of Impact Damage on the Room-Temperature Fatigue Behavior of $\gamma$-TiAl
}

\author{
TREVOR S. HARDING and J. WAYNE JONES
}

The relationship between impact damage and the fatigue behavior of $\gamma$-TiAl has been examined. Axial fatigue specimens fabricated from cast Ti-47.9Al-2.0Cr-1.9Nb (to be referred to as 48-2-2) and Ti-47.3Al-2.2Nb-0.5Mn-0.4W-0.4Mo-0.23Si (to be referred to as WMS) alloys were damaged by impact under controlled conditions with a 60 deg wedge-shaped indenter to simulate assembly-related damage in low-pressure turbine blades. The level of damage produced was quantified and found to correlate well with the peak load of the impact event. The WMS alloy exhibited a greater resistance to impact damage due to its higher yield strength and lamellar microstructure. A measure of the ambient-temperature fatigue failure stress in the alloys was obtained by standard fatigue testing employing a step-loading approach. The failure stress of the WMS alloy was greater than that of the 48-2-2 alloy in the undamaged state. The relationship between impact damage and failure stress was examined using a threshold-based approach. These studies indicate that, for damage levels below a transitional flaw size, the failure stress is near that for undamaged specimens. At damage levels greater than the transitional flaw size, the failure stress can be adequately approximated using the threshold stress-intensity range $\left(\Delta K_{T H}\right)$ from long-crack growth testing. Fractographic studies were performed to investigate impact damage and crack-advance mechanisms, which match those observed in other alloys tested at room temperature.

\section{INTRODUCTION}

THE $\gamma$-TiAl alloy is a candidate material for use in gasturbine applications, particularly for low-pressure turbine blades, where the excellent high-temperature, specificstrength retention, and low density of $\gamma$-based alloys can be fully utilized. Additionally, the high specific stiffness of this alloy provides benefits in applications where clearance and damping characteristics are important, such as turbine blades. The combination of weight savings and good mechanical properties has led some to believe that $\gamma$-TiAl is capable of replacing current equiaxed nickel-based superalloys in low-pressure turbine blades without a large degree of redesign of the blade. ${ }^{[1]}$

However, when considering the design of components from $\gamma$-TiAl, damage tolerance is of great importance due to the low ductility and fracture toughness of $\gamma$-based alloys, as well as the sensitivity of fatigue lifetime to changes in stress. ${ }^{[2,3]}$ Accordingly, the high-cycle fatigue (HCF) behavior of these alloys has become an important consideration in recent years. At room temperature, the fatigue-crack growth rate of duplex (equiaxed $\gamma$ and lamellar $\alpha_{2}-\gamma$ ) microstructures is highly sensitive to changes in the stress-intensity range $(\Delta K)$. Lamellar microstructures typically exhibit superior fatigue-crack growth resistance, with less sensitivity to $\Delta K$ and higher threshold stress-intensity-range $\left(\Delta K_{T H}\right)$ values, but also exhibit a greater tendency to suffer from short-crack effects, given the typically larger microstructural unit. ${ }^{[4,5,6]}$

TREVOR S. HARDING, formerly Graduate Student Research Assistant with the Department of Materials Science and Engineering, University of Michigan, is Assistant Professor, Industrial and Manufacturing Engineering and Business Department, Kettering University, Flint, MI 48504-4898. J. WAYNE JONES, Professor, is with the Department of Materials Science and Engineering, University of Michigan, Ann Arbor, MI 48109-2136.
In recent years, HCF has become the leading cause of gas-turbine engine component failure. ${ }^{[7]}$ Turbine blades, due to their elongated geometries, are particularly susceptible to $\mathrm{HCF}$, where frequencies can range from 100 to $3000 \mathrm{~Hz} .{ }^{[8]}$ Many of these failures are initiated from unidentified sources; however, significant proportions are the result of impact damage. Blades in gas-turbine engines, particularly high-pressure turbine blades, are susceptible to several forms of in-service impact damage, including foreign and domestic object damage and assembly-related impact damage. Attempts have been made to simulate the effects of impact damage on the fatigue behavior of turbine blade materials (Ti-8Al-1Mo-1V) with some success. ${ }^{[7,9,10]}$ The majority of these efforts have examined either the effects of machined flaws intended to be representative of an impact-damage site, or have assigned stress-concentration values to impactdamage sites rather than using a crack-growth approach. As engine manufacturers push the limits of material capabilities and introduce new materials for turbine blade applications, a new approach to quantifying the effects of impact damage on the HCF behavior of these materials is likely to be needed. In cases where designers are dealing with materials that have a lower damage tolerance, such as $\gamma$-TiAl, a threshold-based approach may be applicable.

Little research has been conducted to date on any class of materials regarding the fatigue response of specimens following impact damage. Not surprisingly, there are serious questions about how $\gamma$-TiAl will respond in such a scenario if it is to be implemented in low-pressure turbine blades. This article documents efforts to characterize and quantify the effects of impact damage on the fatigue failure stress of $\gamma$-TiAl alloys at room temperature. A further goal of this study was to determine whether a threshold-based approximation of the failure stress could be used to predict actual experimental fatigue results. The room-temperature fatigue response of both a duplex Ti-47.9Al-2.0Cr-1.9Nb alloy 


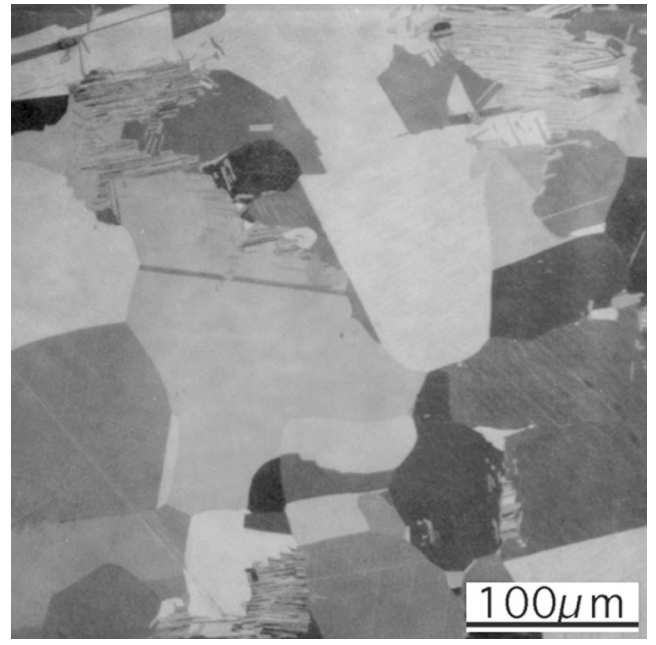

Fig. 1-Duplex microstructure of the 48-2-2 alloy, with $70 \mu$ m equiaxed gamma grains and 6 vol pet lamellar colonies.

(referred to as 48-2-2) and a lamellar Ti-47.3Al-2.2Nb$0.5 \mathrm{Mn}-0.4 \mathrm{~W}-0.4 \mathrm{Mo}-0.23 \mathrm{Si}$ alloy (referred to as WMS) to impacts of varying severity will be discussed.

\section{MATERIALS AND EXPERIMENTAL PROCEDURE}

Two $\gamma$-TiAl alloys were investigated in the present study. The first of these, the 48-2-2 alloy, had a composition of Ti-47.9Al-2.0Cr-1.9Nb (at. pct). ${ }^{[1]}$ This alloy was produced by a vacuum arc remelt method and was investment cast into plates with dimensions of $12.5 \times 100 \times 140 \mathrm{~mm}$ by the Howmet Corporation (Whitehall, MI). These plates were first heat treated in vacuum at $1093{ }^{\circ} \mathrm{C}$ for 5 hours. This was followed by a hot isostatic press (HIP) at $1205^{\circ} \mathrm{C}$ and $172 \mathrm{MPa}$ for 4 hours and a final heat treatment at $1205^{\circ} \mathrm{C}$ for 2 hours, followed by a rapid cool. This processing resulted in the near- $\gamma$ or duplex microstructure seen in Figure 1, with a $\gamma$ grain size of roughly $70 \mu \mathrm{m}$ and about 6 vol pct $\gamma-\alpha_{2}$ lamellar colonies. Additional $\alpha_{2}$ phase was observed along intergranular boundaries, as shown in the backscattered electron (BSE) image in Figure 2. Typical room-temperature

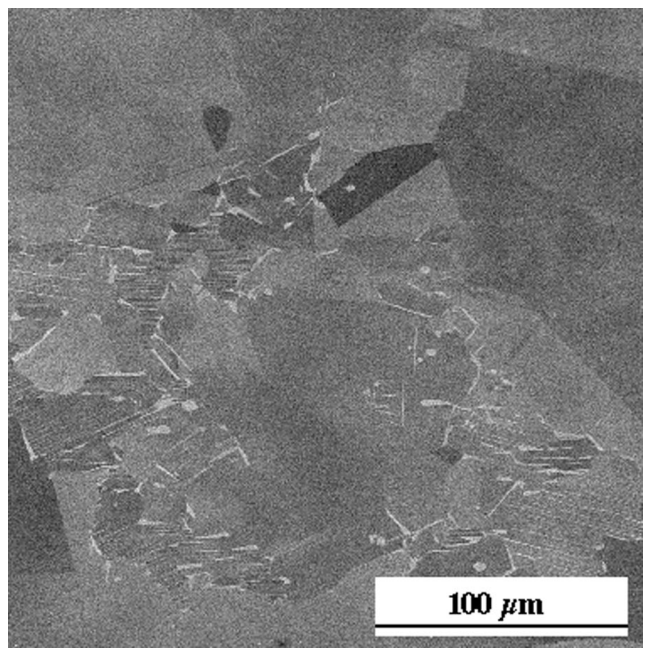

Fig. 2-BSE image of 48-2-2 microstructure showing $\alpha_{2}$ (light gray) phase along $\gamma$ grain boundaries and within $\left(\alpha_{2}-\gamma\right)$ lamellar colonies.
Table I. Room-Temperature Tensile Properties of 48-2-2 and WMS Alloys ${ }^{[13,14]}$

\begin{tabular}{lcccc}
\hline Alloy & $\begin{array}{c}\text { Specimen } \\
\text { Preparation }\end{array}$ & $\begin{array}{c}\text { Yield Strength } \\
(\mathrm{MPa})\end{array}$ & $\begin{array}{c}\text { Tensile } \\
\text { Strength } \\
(\mathrm{MPa})\end{array}$ & $\begin{array}{c}\text { Elongation } \\
(\mathrm{Pct})\end{array}$ \\
\hline $48-2-2$ & $\begin{array}{c}\text { as ground } \\
\text { chem } \\
\text { milled }\end{array}$ & 333 & 436 & 1.8 \\
WMS & 503 & 545 & 0.5 \\
\hline
\end{tabular}

tensile properties from as-ground specimens are provided in Table I.

The second alloy investigated, the WMS alloy, had a composition of Ti-47.3Al-2.2Nb-0.5Mn-0.4W-0.4Mo$0.23 \mathrm{Si}$ (at. pct). ${ }^{[12]}$ This alloy was investment cast into plates with dimensions of $12.5 \times 100 \times 150 \mathrm{~mm}$. Processing following casting consisted of a HIP treatment at $1260{ }^{\circ} \mathrm{C}$ and $172 \mathrm{MPa}$ for 4 hours, followed by a heat treatment of $1010^{\circ} \mathrm{C}$ for 50 hours. The microstructure of this alloy, shown in Figure 3, was near-fully lamellar in character, with a lamellar colony size of $165 \mu \mathrm{m}$ and small $\gamma$ grains along colony boundaries. A small volume fraction of the $\mathrm{B} 2$ phase was observed along triple points of lamellar colonies, as seen in the BSE image of Figure 4. From the image, interdendritic segregation can also be observed as the darker regions. Typical room-temperature tensile properties from chem-milled specimens are listed in Table I.

Dog bone-shaped fatigue specimens were prepared by electrodischarge machining (EDM) blanks from the cast plates of material. Specimens were then low-stress ground to the desired dimensions, followed by a hand polish until a 600-grit finish was attained. Each specimen was then electropolished in a solution of $60 \mathrm{pct}$ methanol, $35 \mathrm{pct} n$-butanol, and 5 pct perchloric acid at $-50{ }^{\circ} \mathrm{C}$ and $25 \mathrm{~V}$.

Damage was introduced into the specimens by one of two means-low-speed drop-weight impacts or "quasi-static" impacts-at Carnegie-Mellon University (Pittsburgh, PA). Low-speed drop-weight impact tests were performed on an instrumented impact apparatus, which includes a dynamic load cell for acquiring contact-force data during the impact.

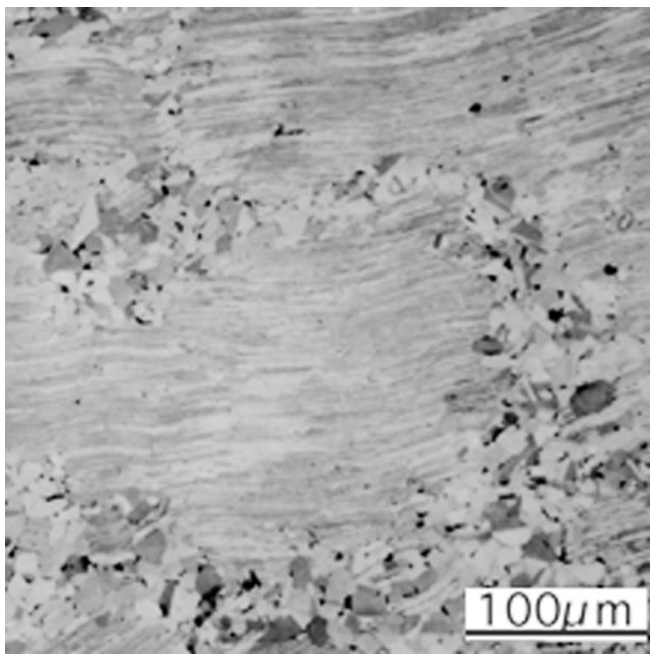

Fig. 3 Lamellar microstructure of the WMS alloy showing $165 \mu \mathrm{m}$ lamellar colony size surrounded by interlamellar $\gamma$ grains. 


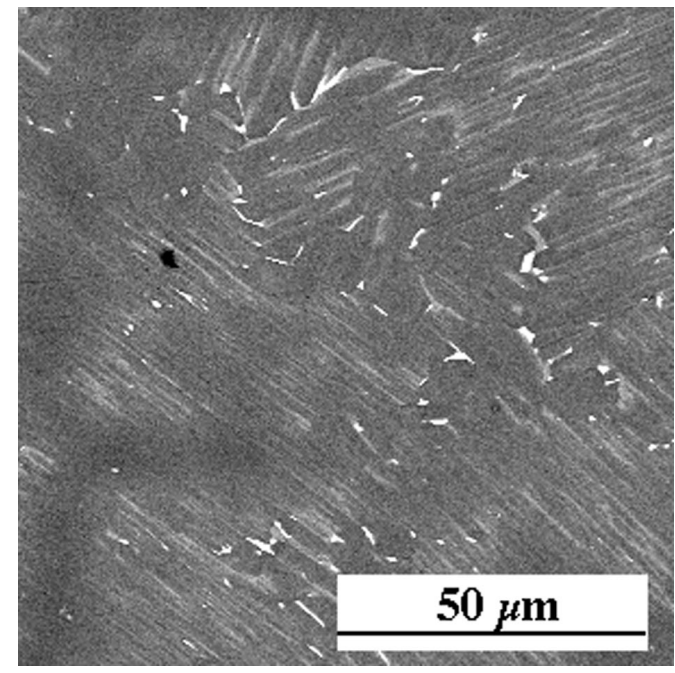

Fig. 4-BSE image of lamellar WMS alloy showing existence of B2 phase (white spots) and interdendritic segregation (dark regions).

Specimens were impacted with a hardened-steel, $60 \mathrm{deg}$ flank-angle wedge, dropped from a height calculated to give a specific impact energy. The duration of the impact was on the order of $10^{-3} \mathrm{~s}$. The load-time trace from the load cell was recorded on a computer, and the maximum load during impact was determined. This peak impact load is an important parameter for later characterization of the resulting damage.

Quasi-static impacts were conducted on a mechanical testing machine and involved indenting the specimen with the same steel wedge at loading rates 500 times slower than those in the low-speed impacts. The load data were again recorded via a load cell and computer. These data were again used to determine the peak impact load during the indentation. Quasi-static impacting was found to provide a more-reproducible method of introducing damage that was equivalent in appearance to that produced during low-speed drop-weight impacts. The loading rate appears to have little effect on either the tensile ductility or the damage mechanism in $\gamma$-TiAl, which has been confirmed in tensile tests on similar alloys. ${ }^{[3,15]}$

Damage from an impact was characterized by both optical microscopy and scanning electron microscopy. Damage is defined in terms of certain parameters that can be related to the peak impact load. These parameters, shown schematically in Figure 5, include the depth of the indent, the length of cracks ahead of the indent, and the extent of plastic deformation around the impact site. Damage generated from the impact was characterized using the secondary electron detector on a scanning electron microscope (SEM) with a field-emission gun. The indent depth $(D)$ and indent-tip radius $(\rho)$ for every impact site were measured in the SEM. The final indent depth is taken as the average of the measured values from both sides of the specimen. The indent-tip crack length $(a)$ is defined as the projected crack length from the tip of the indent to the tip of the crack. The length of the indent-tip crack is also averaged from both sides of the specimen. An effective crack length $\left(a_{\text {eff }}\right)$ is defined here as the sum of the indent depth and indent-tip crack length described previously $\left(a_{\mathrm{eff}}=a+D\right)$. In addition to this measure of damage, many isolated cracks were often

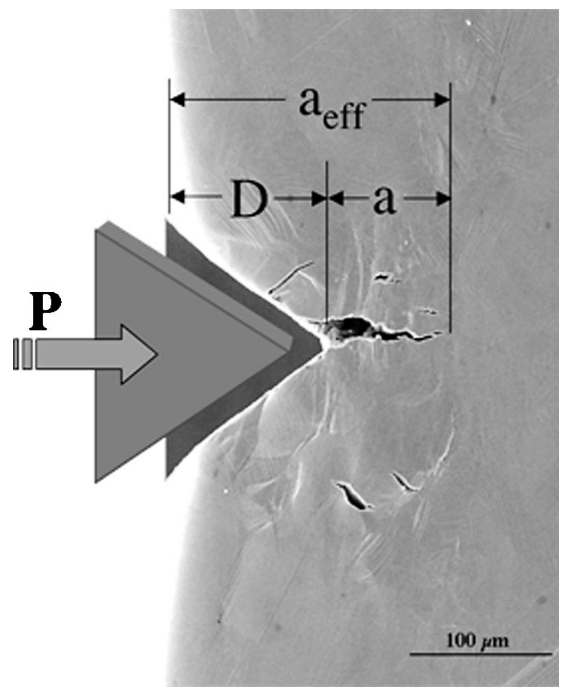

Fig. 5-Schematic diagram of damage zone resulting from impact by a 60 deg wedge.

observed throughout the plastic zone. These cracks do not appear to be connected to the indent, at least on the specimen surface.

A lower bound of the plastic-zone size was estimated by measuring the distance from the indent tip to the farthest extent of visible slip lines in $\gamma$ grains on the surface of the specimen, using a polarized light in an optical microscope. The size of the plastic zone was found to increase linearly with increasing peak impact load and was generally larger in the 48-2-2 alloy for a given peak impact load.

The SEM was also used for fractographic observations. Information regarding the crack propagation mode from the impact site was noted. In addition, the presence and extent of features that may be related to the impact event was investigated.

Fatigue tests were performed using the "step-test" method, which is a step-loading fatigue test intended to determine the endurance limit of a material with a minimum of specimens. ${ }^{[16]}$ The step test is, therefore, imperative to developing fatigue failure-stress data over the wide range of peak impact loads investigated in this research. The method involved testing a specimen at a particular stress level for a predetermined number of cycles, or a cycle block, at an initial maximum stress estimated to be 75 pct of the threshold stress, based on a fracture-mechanics calculation. If the specimen survives this first cycle block, the maximum cyclic stress is increased by a set increment, while the load ratio is kept constant, and the test is run for another block. The test continues in this way until the specimen fails. Fatigue failure stress is then defined as the highest stress level at which a specimen was able to survive the full $10^{5}$ cycle block. Given the flatness of stress-lifetime fatigue plots for various $\gamma$ TiAl alloys,${ }^{[3,17]}$ this was thought to be a reasonable approximation of the endurance limit and, thus, the threshold stress of a damaged specimen. In these experiments, the cycle block was $10^{5}$ cycles and the incremental stress increase was $10 \mathrm{MPa}$. All tests were conducted on a servo-hydraulic fatigue test machine at room temperature in air. Tests were run at a frequency of $20 \mathrm{~Hz}$ and with a constant load ratio of $R=0.1$. 


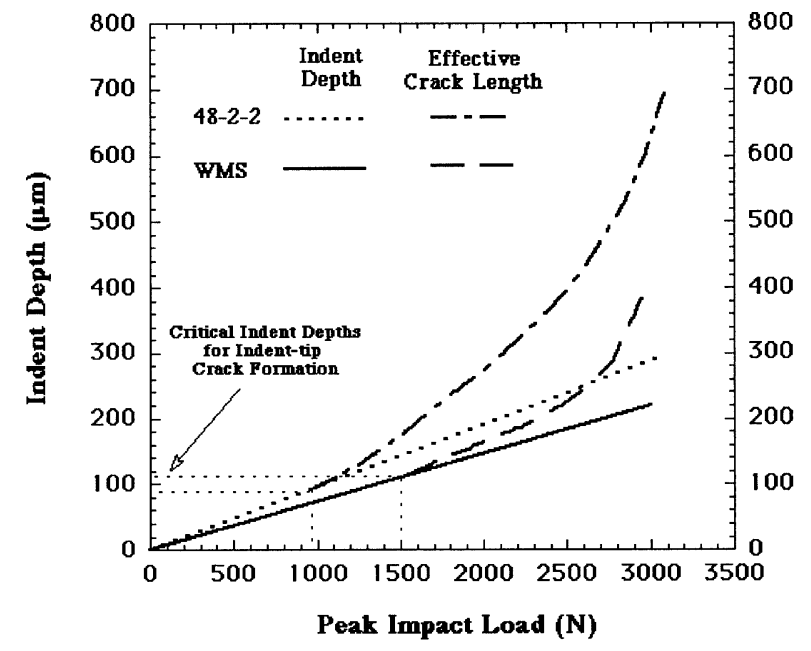

Fig. 6-Correlation between peak impact load and the critical damage parameters for both the duplex 48-2-2 alloy and the lamellar WMS alloy.

\section{RESULTS}

\section{A. Impact-Damage Characterization}

Impact results in the formation of an indent surrounded by a large zone of plastic deformation and, in the case of more-severe impacts, cracks located both at the tip of the indent and scattered throughout the plastic zone. Characterization of the damage zone involves measurement of the depth of the indent, the size and position of all cracks, and the extent of plastic deformation. The indent-tip crack typically initiates within 30 to $40 \mu \mathrm{m}$ of the tip of the indent along the indent face, where the stresses and strains are highly localized and sufficient to cause fracture of the local material.

Trend lines for indent-depth and effective crack-length data are shown schematically in Figure 6. In the case of the duplex 48-2-2 alloy, there is a distinct linear relationship between the indent depth and the peak impact load. Furthermore, the indent-tip crack only appears to be formed above a peak impact load of around $1000 \mathrm{~N}$ for the specimen geometry examined here. This suggests that, for low-severity impacts $(<1000 \mathrm{~N})$, the material will dent, but no surface cracks will form. For impacts beyond this low-severity limit, the effective crack length increases rapidly, until, at the mostsevere impacts investigated, the indent-tip crack is of the same magnitude as the indent depth. Other impact geometries must be investigated before these observations can be generalized. The indent depth also follows a linear trend with peak impact load in the WMS alloy, but the depths are lower compared to the 48-2-2 alloy, which may result from the higher yield strength of the WMS alloy. The formation of indent-tip cracks in the lamellar WMS alloy is only observed for impacts with peak impact loads greater than roughly $1600 \mathrm{~N}$, which is significantly higher than those observed in the 48-2-2 alloy.

These observations suggest that the 48-2-2 alloy is more susceptible to the formation and propagation of indent-tip cracks. However, when examining the effective crack length as a function of indent depth, the formation of indent-tip cracks at the critical peak impact load occurred at nearly the same indent depth, regardless of the alloy. This critical indent depth is in the range from 80 to $110 \mu \mathrm{m}$. Thus, the

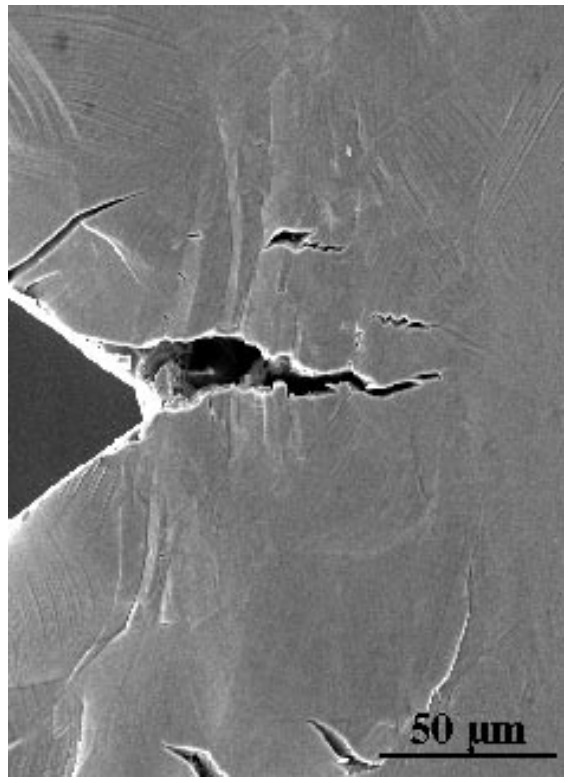

(a)

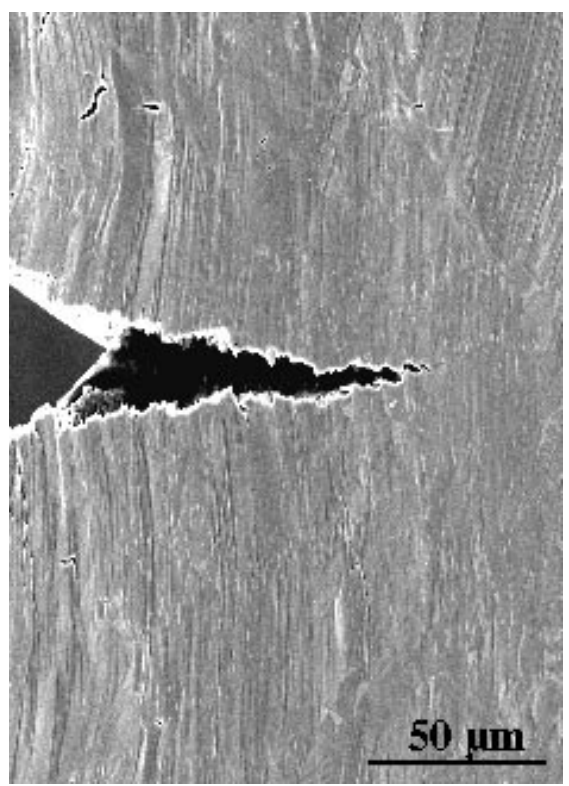

(b)

Fig. 7-Typical damage zones in the ( $a$ ) 48-2-2 alloy and (b) WMS alloy.

formation of indent-tip cracks resulting from impact with this particular geometry appears to be dependent on the depth of the indent, which, in turn, is a function of the peak impact load and the material yield strength.

In the 48-2-2 alloy, indent-tip cracks were primarily transgranular in nature. A typical damage zone is shown in Figure 7. In some cases, the crack had formed intergranularly at the tip of the indent and then propagated transgranularly. This may be caused by the highly localized strains near the indent tip, which cause two misaligned grains to fracture along the grain boundary. Low-level impacts $(<1000 \mathrm{~N})$ did not generate indent-tip cracks.

In addition to the indent-tip crack, isolated cracks were also observed throughout the damage zone. These cracks appear to be isolated from the indent, based upon both specimen-surface and fracture-surface observations. Isolated 
cracks within the plastic zone were often intergranular in nature. A moderate dependence upon peak impact load was observed for the formation of these cracks.

In the WMS alloy, indent-tip cracks show evidence of interlamellar and translamellar fracture, with possible transgranular cleavage through individual gamma grains. A typical damage zone from a WMS specimen is shown in Figure 7. Low-severity impacts $(<1600 \mathrm{~N})$ failed to produce indenttip cracks in this alloy. Isolated cracks, like those in the 482-2 alloy, were also observed in the WMS alloy, but the fracture mode varied.

\section{B. Correlations between Impact-Damage Parameters and Fatigue}

1. A threshold-based model for fatigue failure stress

A threshold stress intensity-based approach was used to estimate fatigue failure stress in damaged $\gamma$-TiAl alloys from damage parameters, rather than a stress concentration-based approach, such as that used by Nicholas et al. ${ }^{[10]}$ Attempts to calculate an elastic-stress-concentration factor for these notch-like indents resulted in values of $k_{t}=10$ to $12,{ }^{[18]}$ which is inconsistent with the degreee of reduction in fatigue strength measured from step tests of damaged specimens. These high values are the result of the severe sharpness of the indents, which have a tip radius on the order of 10 to $30 \mu \mathrm{m}$, generated by the impact.

Smith and Miller ${ }^{[19,20]}$ proposed that sharp notches create a stress field around the notch tip, the size of which is determined by

$$
r=0.13 \sqrt{\rho D}
$$

where $r$ is the radius of the stress field measured from the indent tip, $\rho$ is the indent-tip radius, and $D$ is the indent depth.

Within this stress field, the stress-concentration factor must be applied to the applied stress to determine the stress intensity of an indent-tip crack. However, if the crack exceeds this field, the stress intensity is determined from the applied stress and the sum of the indent depth and indenttip crack length, or the effective crack length. From measurements of the impacted $\gamma$-TiAl specimens, the notch stress field was estimated to lie within the range from 4 to $12 \mu \mathrm{m}$. This value is generally smaller than the majority of indenttip cracks observed, and, thus, the stress-intensity-factor range of the damage zone was estimated by

$$
\begin{aligned}
\Delta K_{I} & =F\left(\frac{a+D}{W}\right) \Delta \sigma \sqrt{\pi(a+D)} \\
& =F\left(\frac{a_{\mathrm{eff}}}{W}\right) \sigma_{\max }(1-R) \sqrt{\pi a_{\mathrm{eff}}}
\end{aligned}
$$

This model assumes that the indent-tip crack is a throughthickness crack. Although this is clearly an oversimplification of the problem, the prediction still appears to be reasonably good. A threshold-based approach is intended to provide a lower bound on the fatigue strength of a material in the presence of impact damage. This threshold stress level can be calculated using the long-crack threshold-stress-intensity range using the following equation:

$$
\sigma_{T H}=\left(\frac{\Delta K_{T H}}{F\left(\frac{a_{\mathrm{eff}}}{W}\right)(1-R) \sqrt{\pi a_{\mathrm{eff}}}}\right)
$$

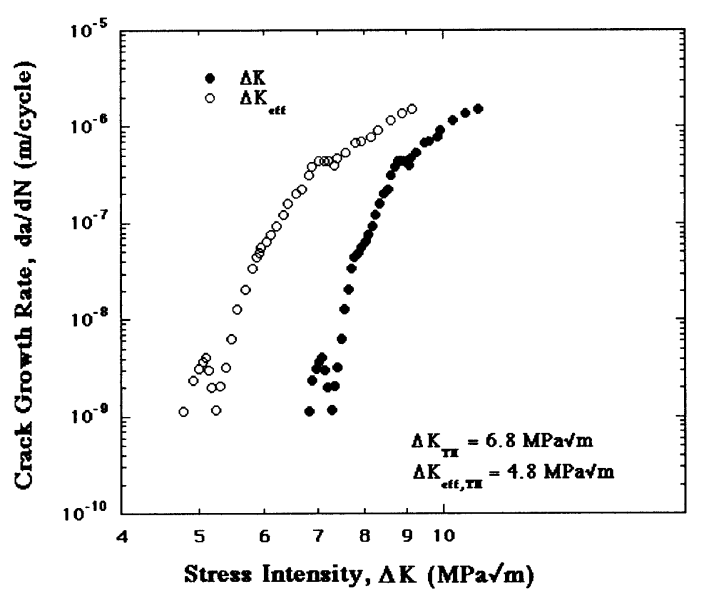

(a)

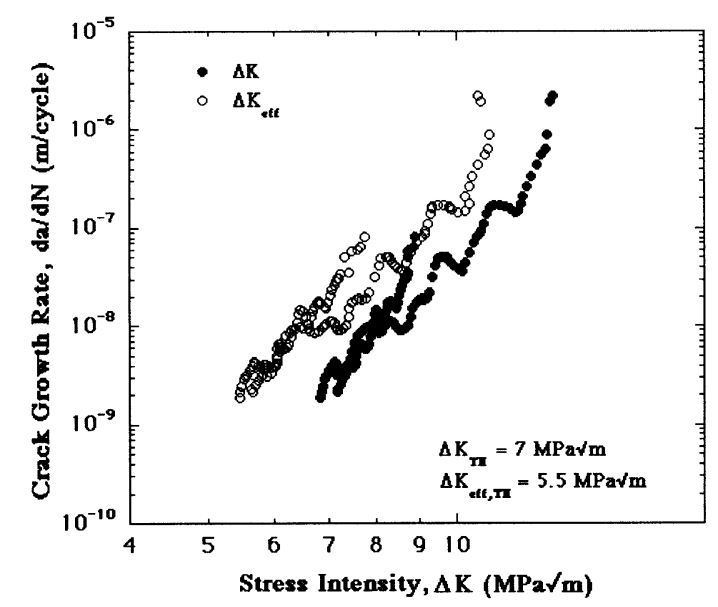

(b)

Fig. 8-Room-temperature fatigue crack growth rate data for the ( $a$ ) 48$2-2$ alloy ${ }^{[21]}$ and $(b)$ WMS alloy. ${ }^{[14]}$

where $\Delta K_{T H}$ is the threshold-stress-intensity-factor range taken from the long-crack growth data shown in Figure 8. ${ }^{[21]}$ A similar equation can be developed using an effective threshold-stress-intensity-factor range $\left(\Delta K_{\mathrm{eff}, T H}\right)$, considering closure-corrected fatigue-crack growth data.

$$
\sigma_{\mathrm{eff}, T H}=\left(\frac{\Delta K_{\mathrm{eff}, T H}}{F\left(\frac{a_{\mathrm{eff}}}{W}\right)(1-R) \sqrt{\pi a_{\mathrm{eff}}}}\right)
$$

\section{Effect of impact damage on fatigue failure stress}

The reduction in fatigue failure stress caused by impact damage was correlated to the effective crack length. Figure 9 compares the fatigue failure stress of the 48-2-2 alloy to the effective crack length, in a form modified from that developed by Kitagawa and Takahashi. ${ }^{[22]}$ From the plot, it can be seen that, in cases where the effective crack length exceeds a transitional value, the fatigue failure stress can be reasonably predicted using a threshold-based approach. The transitional damage level is defined as the crack length at which the threshold stress is equal to the failure stress of an undamaged material. Thus, the transitional flaw size can be estimated by the following equation: 


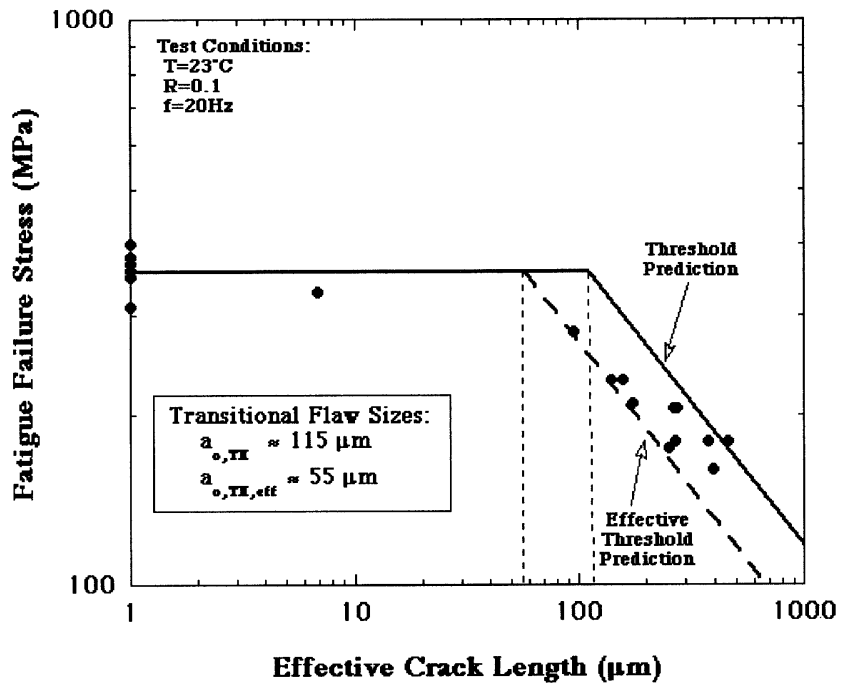

Fig. 9-Reduction in fatigue failure stress of 48-2-2 $\gamma$-TiAl alloy based upon the effective crack length following impact. Beyond the transitional flaw sizes, the threshold and effective threshold predictions bound the effect of impact damage on fatigue.

$$
a_{0, T H}=\frac{1}{\pi}\left(\frac{\Delta K_{T H}}{F\left(\frac{a_{\mathrm{eff}}}{W}\right)(1-R) \sigma_{f}}\right)^{2}
$$

where $\sigma_{f}$ is the maximum cyclic failure stress of the undamaged material. A similar equation can be developed for $a_{0, \mathrm{eff}, T H}$. The transitional damage level is termed $a_{0, T H}$ or $a_{0, \text { eff, } T H}$, respectively, depending on whether threshold (solid line in Figure 9) or effective threshold (dashed line in Figure 9) long-crack data are used in the estimate. These lines represent the threshold stress as determined from Eqs. [3] and [4]. In the case of the 48-2-2 alloy, the transitional damage level appears to have values for $a_{0, T H}$ and $a_{0, \text { eff }, T H}$ of 115 and $55 \mu \mathrm{m}$, respectively. At damage levels greater than these transitional flaw sizes, the data are well bounded by the threshold and effective threshold prediction.

For effective crack lengths below the transitional damage levels, the failure stress tends to be unaffected by the impact event and approaches the fatigue failure stress for undamaged material. The failure stress for undamaged specimens was determined from step tests, in a manner identical to that used for damaged specimens. On average, this undamaged failure stress in the 48-2-2 alloy is approximately $360 \mathrm{MPa}$.

In the WMS alloy, the theoretical transitional damage level is about $45 \mu \mathrm{m}$, as shown in Figure 10. The effective transitional flaw size is approximately $30 \mu \mathrm{m}$. These values are calculated from Eq. [5]. For damage levels greater than $a_{0, T H}$, the fatigue failure stress seems to be slightly higher than that predicted by Eq. [3]. Despite this discrepancy, there is clearly a strong correlation between the effective crack length and the subsequent fatigue failure-stress data at crack lengths greater than the transitional flaw size. Below the transitional flaw size, the data are seen to approach the fatigue failure stress of undamaged material in an asymptotic fashion. The fatigue failure stress of undamaged WMS material was $585 \mathrm{MPa}$.

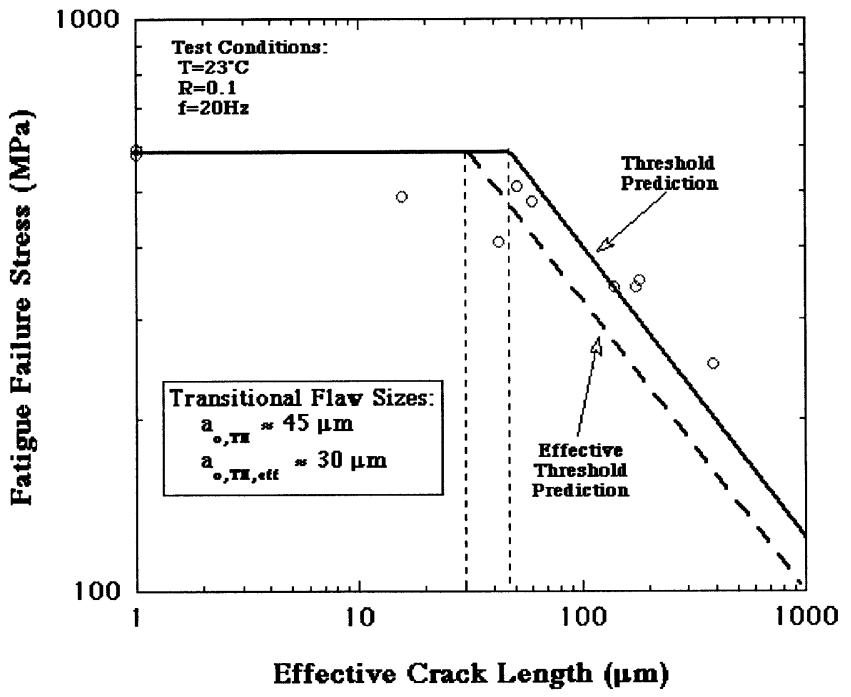

Fig. 10-Reduction in fatigue failure stress of WMS $\gamma$-TiAl alloy based upon the effective crack length following impact. A strong correlation between the damage parameter and failure stress is observed.

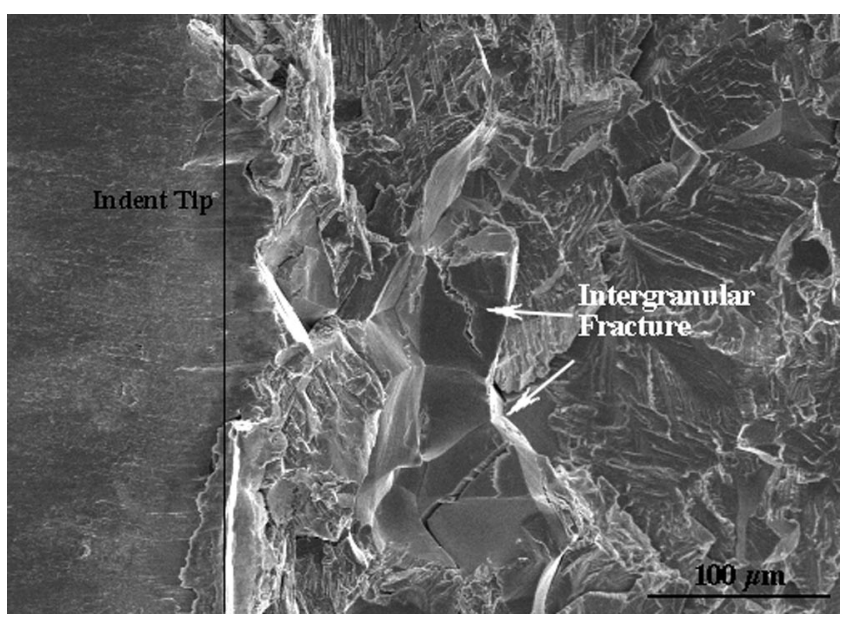

Fig. 11-Appearance of impact damage in the near indent-tip region of a failed 48-2-2 specimen. Crack propagation is left to right in the figure.

\section{Fractographic Observations}

Figure 11 shows the fracture surface of a 48-2-2 alloy specimen subjected to a high-severity impact followed by fatigue. This fractograph, taken near the indent tip (seen on the left-hand side), shows evidence of both transgranular cleavage and intergranular fracture in the impact-damaged region of the specimen. The transgranular cleavage sites indicate that the indent-tip crack propagates from the indent tip toward the interior of the specimen (from the left- to the right-hand side in the figure). Furthermore, the intergranular fracture sites have only been observed in the near-indenttip region, suggesting that they are either indicative of impact damage or are a result of near-threshold crack growth. The relative amount of intergranular fracture tends to increase with peak impact load; however, this has not been established quantitatively. Regions exhibiting parallel slip markings have also been observed within fractured gamma grains. The fatigue region in impacted 48-2-2 specimens, shown in 


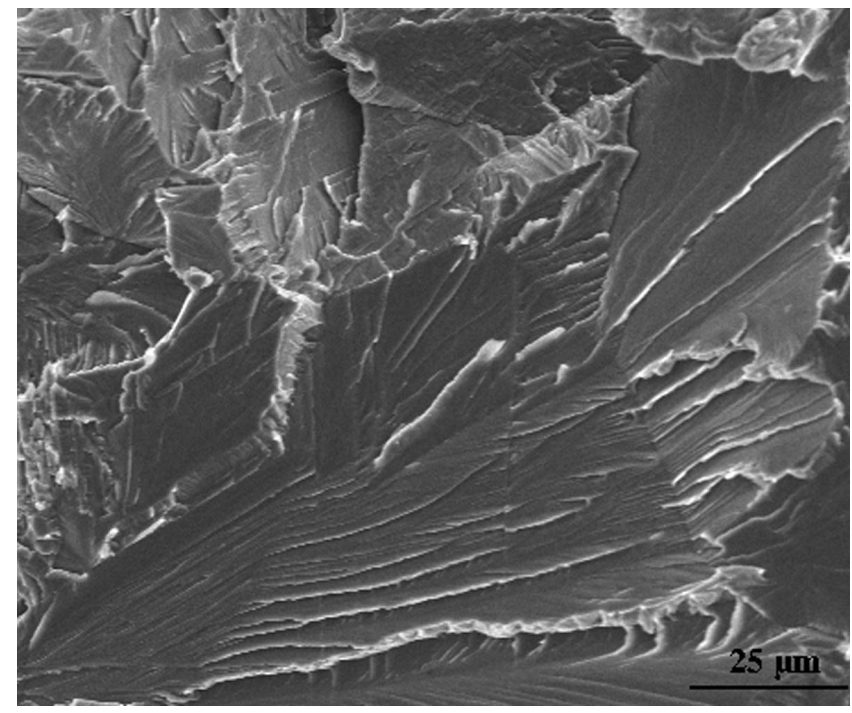

Fig. 12-Appearance of fatigue crack growth region of impact damaged 48-2-2 specimens following room-temperature fatigue. The dominant propagation mechanism is transgranular cleavage. Crack propagation is left to right in the figure.

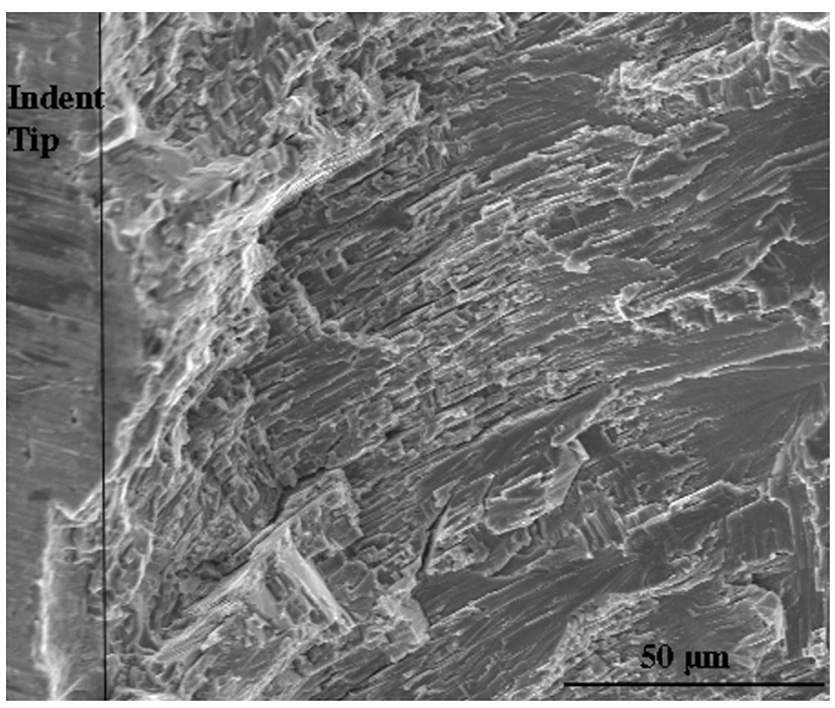

Fig. 13-Near indent-tip fracture surface of an impacted WMS specimen. Crack propagation is from left to right in the figure.

Figure 12, exhibits transgranular cleavage with increasing secondary cracking as the crack progresses, resulting in a tortuous fracture surface in the overload region. There are no signs of intergranular cracking in this region.

Examination of the indent-tip region of the WMS alloy fracture surfaces failed to reveal unique features that might point to damage caused by the impact event. A typical indenttip fractograph is shown in Figure 13. The indent-tip region consists primarily of translamellar fracture with a moderate degree of interlamellar fracture. This is quite similar to the fatigue-crack-propagation region, although the degree to which the crack path is tortuous appears to be higher in the near-indent-tip region. Translamellar and interlamellar fracture dominated the fatigue-crack-propagation morphology in the impacted WMS alloy, as shown in Figure 14, with increasing amounts of interlamellar fracture occurring

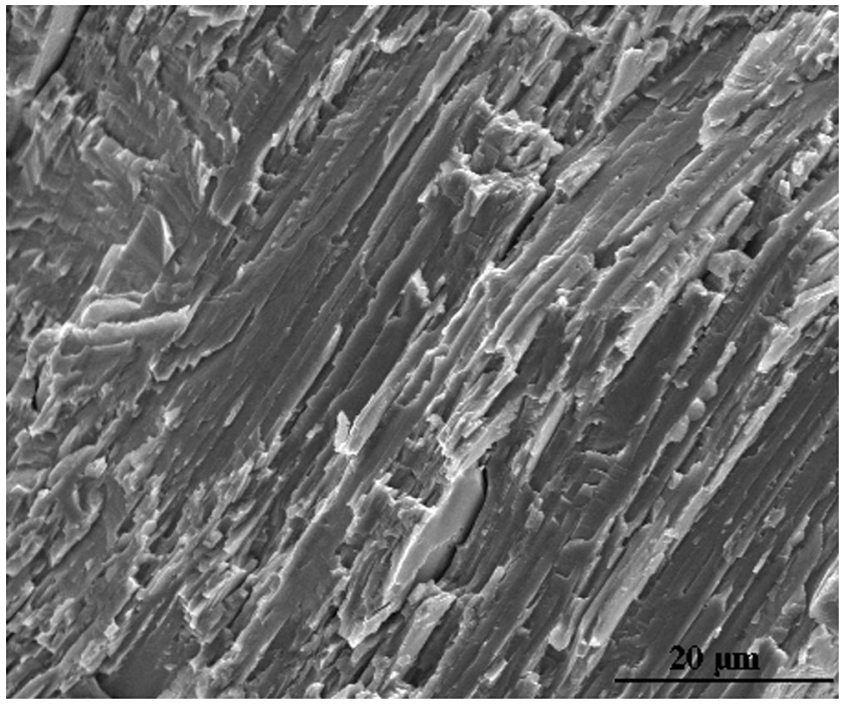

Fig. 14-Mixed translamellar/interlamellar fracture mechanism observed in fatigue crack growth region of WMS fracture surface following roomtemperature testing. Fatigue crack propagation is from left to right in the figure.

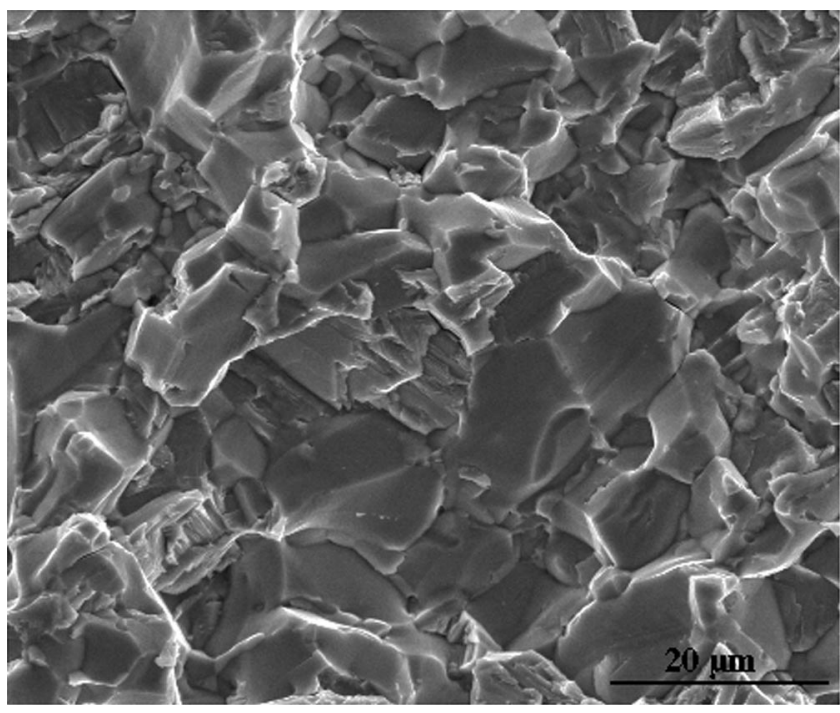

Fig. 15-Intergranular fracture becomes the dominant crack growth mechanism when the fatigue crack passes through a "packet" of interlamellar equiaxed $\gamma$ grains. Fatigue crack propagation is from left to right in the figure.

as the crack progressed. At times, the fatigue crack intersected packets of interlamellar gamma grains. The dominant propagation mechanism through these regions was intergranular fracture, as shown in Figure 15.

\section{DISCUSSION}

\section{A. Impact-Damage Formation}

As described previously, the impact event results in the formation of an indent, a zone of plastic deformation, and, in the case of more-severe impacts, cracks within the plastic zone. A strong linear trend between peak impact load and indent depth is observed for both the 48-2-2 and WMS alloys. Analysis of the data reveals that the following linear 
relationships between peak impact load $(P)$ and indent depth can be established:

$$
\begin{aligned}
& P=10.4 D(48-2-2 \text { alloy }) \\
& P=13.7 D(\text { WMS alloy })
\end{aligned}
$$

These equations are in good agreement with analytical approximations derived by Rubal and Steif of the load-indent depth relation for the same alloys and damage procedure. ${ }^{[23]}$ The difference in the measured indent-depth coefficients between the two materials is a reflection of the higher yield strength of the WMS alloy.

The dependence of the initiation of indent-tip cracks on a critical indent depth is likely related to the ability of the alloy to sustain large amounts of plastic deformation at the indent tip. A wedge-shaped indenter, such as that used in the present work, will produce a strain field that is a direct function of the shape of the indenter and the depth of the indent. In the case of a wedge, the maximum strain magnitude will be determined by the wedge-flank angle $(60 \mathrm{deg})$ and will decay rapidly away from the indent tip. ${ }^{[2]}$ The formation of a crack at the indent tip likely requires that two conditions be met. First, a critical strain $\left(\varepsilon_{c}\right)$ must be exceeded by the plastic strains developed at the indent tip. This critical strain is probably related in some way to the material ductility. Given that the ductilities of the duplex 48-2-2 and near-fully lamellar WMS alloys are similar, it can be roughly estimated that the critical-strain parameter should be nearly the same for both alloys. Therefore, it is not suprising that the critical indent depth for the formation of an indent-tip crack is almost equivalent for both alloys.

The second criteria requires that the distance over which the near-indent-tip strain is greater than $\varepsilon_{c}$ exceeds a criticallength parameter $\left(x_{c}\right)$. This critical-length parameter is likely related to the microstructural-length scale. If both criteria are met, a crack should form at the indent tip, as shown schematically in Figure 16. The critical-length parameter may be defined by the pileup of dislocations along critical barriers near the indent tip, such as $\gamma$ or lamellar grain boundaries and $\alpha_{2} / \gamma$ or $\gamma / \gamma_{T}$ lamellar interfaces. A criterion for indent-tip crack initiation could be developed by computing the stresses created by such a pileup and comparing them to an appropriate fracture strength for specific mechanisms on slip planes or boundaries. ${ }^{[25]}$ The formation of such a crack is based upon the criteria that the overall stored energy of the system be reduced and depends upon several factors, including the type of barrier intersected by the dislocations, orientation of the slip plane and barrier, and the material. ${ }^{[26]}$ Such a model is beyond the scope of this article, however.

In the duplex alloy, plastic strain is primarily accommodated by planar slip in the equiaxed gamma grains, which have insufficient slip systems, leading to crack initiation both transgranularly, as shown in Figure 17(a), and at the boundaries of grains with misaligned slip bands, as shown in Figure 17(b). ${ }^{[27]}$ Pollock et al. observed the initiation of cracks at notches under static loading following significant plastic straining in the same duplex alloy (48-2-2). ${ }^{[28]}$ These cracks initiated primarily by a transgranular cleavage-like mode in highly strained grains or by intergranular decohesion associated with slip-band impingement at the interface of two misaligned $\gamma$ grains. Furthermore, given that the gamma grain size is on the order of $65 \mu \mathrm{m}$, only a few grains will

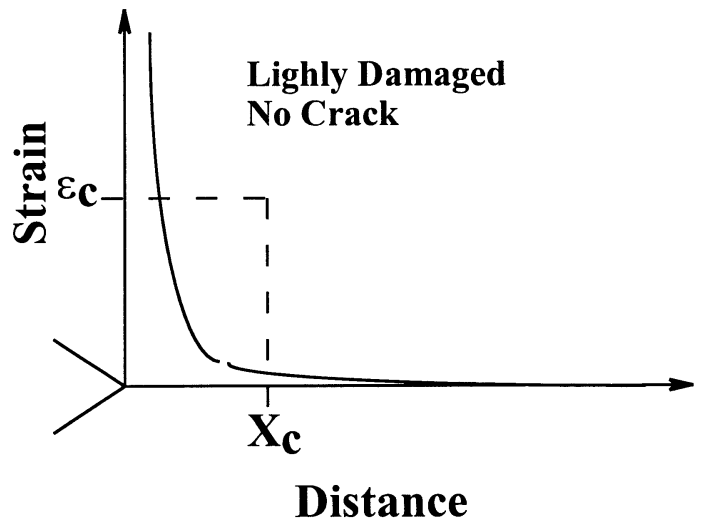

(a)

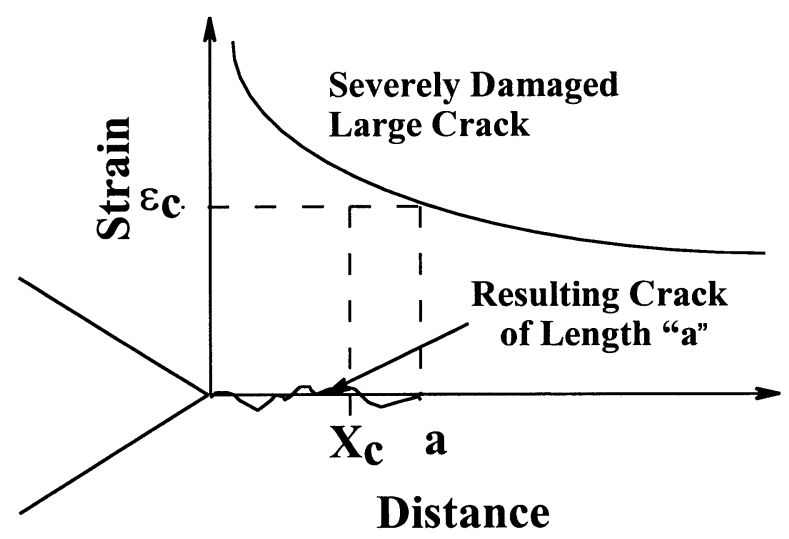

(b)

Fig. 16-Schematic representation of the critical damage criteria required to form an indent-tip crack. Comparison is made between $(a)$ lightly damaged specimens and $(b)$ severely damaged specimens. The formation of an indenttip crack of length $a$ requires that the near indent-tip strain exceed the critical strain, $\varepsilon_{c}$, over at least the scale of the critical length parameter, $x_{c}$.

control the fracture process at the indent tip. Thus, extensive slip within one or two properly oriented gamma grains can lead to fracture at strains on the order of the yield strain. ${ }^{[2]}$

In the lamellar alloy, cracks generally initiate by translamellar fracture, through translamellar slip on $\{111\}<1 \overline{1} 0]$ easy-slip systems. ${ }^{[30]}$ The indentations are oriented roughly perpendicular to the lamellar plates and, as such, plastic deformation must be accommodated by translamellar slip. Given that this form of slip is more difficult than interlamellar slip, due to the larger number of barriers $\left(\gamma / \gamma_{T}\right.$ interfaces and $\alpha_{2}$ plates), the associated flow stresses will be higher, and translamellar microcracks are likely to form at the indent tip. This sort of initiation mechanism is illustrated in Figure 18.

Thus, the higher yield strength of the lamellar alloy means that not only are indents less deep for a given peak impact load, but also that the formation of indent-tip cracks requires significantly higher loads. Further investigations of the actual near-indent-tip strains are needed to quantify this argument; however, this may prove difficult, given the inhomogeneous nature of the microstructures and the anisotropic properties of individual lamellar colonies.

The length of the crack formed should correspond to the distance over which the strain exceeds $\varepsilon_{c}$, as shown in Figure 16. This would suggest that the indent-tip crack length should scale linearly with the indent depth and peak impact load. 


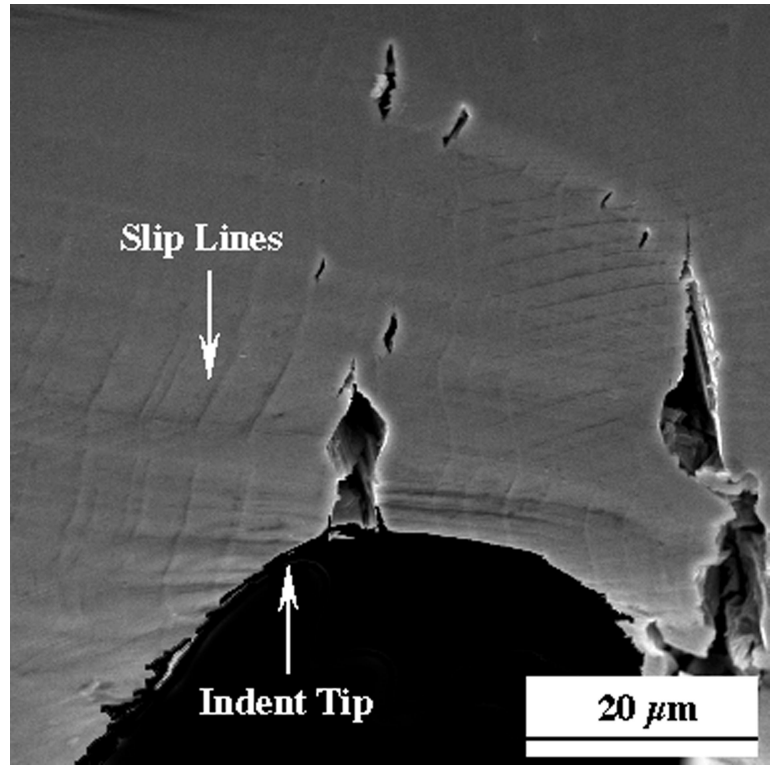

(a)

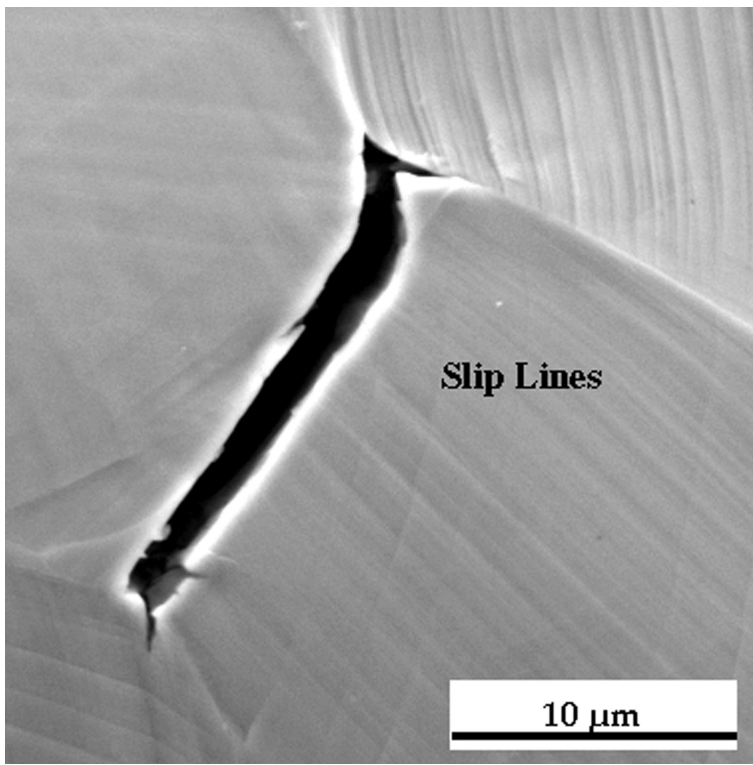

(b)

Fig. 17-Mechanisms for crack initiation in the duplex 48-2-2 alloy: ( $a$ ) transgranular cleavage along intense slip bands emanating from the indent tip, and $(b)$ intergranular fracture due to incompatible slip at $\gamma$ grain boundaries.

However, Figure 6 clearly shows that indent-tip crack length increases in a nonlinear way with increasing peak impact load. This phenomenon can be understood by recognizing that, once a crack is initiated at the indent tip, further loading of the wedge serves to force open the crack mouth, in addition to increasing the near-indent-tip strains. Thus, the cracktip stress intensity is increased, causing the crack to extend further when the material fracture toughness is exceeded. The relative toughness of these two materials can be examined in terms of the relevant fracture modes.

In the case of the 48-2-2 duplex alloy, the majority of indent-tip cracks propagate in a transgranular fashion. Rogers and Bowen ${ }^{[31]}$ have reported that cracks in duplex $\gamma$

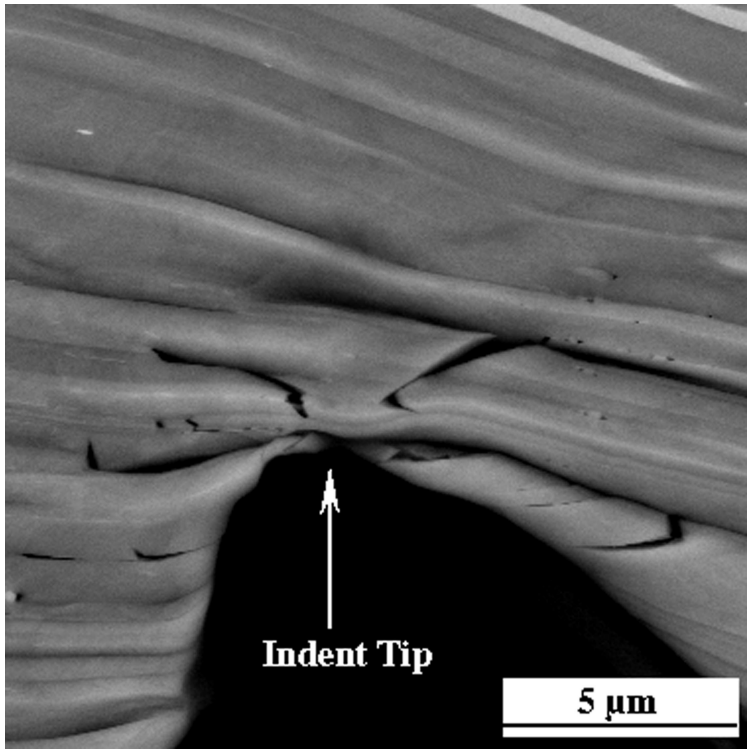

Fig. 18-Backscatter electron image of the initiation of indent-tip cracks by translamellar fracture in the lamellar WMS alloy.

alloys, in order to avoid propagating through lamellar colonies, will preferentially travel along cleavage planes within gamma grains. This suggests that transgranular cleavage is a low-energy form of crack growth and is likely the cause of the lower fracture toughness frequently observed in duplex microstructures. ${ }^{[2,32]}$ Furthermore, indent-tip cracks in the duplex 48-2-2 alloy exhibit limited crack branching and/or ligament formation, and, from fractographic analysis, show a slightly less tortuous crack path than that observed in the lamellar WMS alloy. In a few cases, a crack would intersect a weak $\gamma$ grain boundary, resulting in a crack extension that was significantly greater than anticipated. Therefore, it must be stipulated that, although the crack length can be roughly correlated to the indent depth and peak impact load, the local near-indent-tip microstructure is crucially important.

Indent-tip cracks in the lamellar WMS alloy must cross individual lamellar laths, which may have greatly different orientations from colony to colony. The local fracture mechanism, therefore, is highly dependent on the orientation of particular lamellar colonies. Several investigators have shown the significant influence of lamellar colony orientation on the crack-propagation mechanism. ${ }^{[33-36]}$ The result is a mix of inter- and translamellar fracture of lamellar laths, leading to a very tortuous crack path and, thus, greater energy absorbed in crack formation. Likewise, cracks in the lamellar alloy showed more evidence of ligament formation and crack branching. It was observed that if the crack intersected an interlamellar boundary lying nearly in the same plane as the crack, it would extend further than predicted. This is not suprising, considering that interlamellar fracture has an inherently low crack-growth resistance compared to translamellar fracture. ${ }^{[37]}$

\section{B. Fatigue from Impact-Damage Sites}

Comparison of the initial surface measurements of impact damage to the magnitude of fatigue failure stress reductions indicates that the effect of impacts on $\gamma$-TiAl alloys can be reasonably approximated using a long-crack threshold-based 
model, assuming those impacts generate a level of damage greater than the transitional flaw size. In the case of the 482-2 alloy, the values of $a_{0, T H}$ and $a_{0, \text { effTH }}$ were 115 and 55 $\mu \mathrm{m}$, respectively. Given that the data are bounded by both the $\sigma_{T H}$ and $\sigma_{\text {eff, } T H}$ predictions in Figure 9, it is conceivable that cracks within this range are, in fact, physically short cracks that have not yet developed sufficient closure to behave as long cracks. This region of physically short-crack behavior appears to extend from $a_{\mathrm{o}, \mathrm{effTH}}(55 \mu \mathrm{m})$ to the point at which the data approach the $\sigma_{T H}$ prediction line $(\sim 500$ $\mu \mathrm{m})$. Thus, one could define the lower bound of long-crack behavior to be at crack sizes greater than $500 \mu \mathrm{m}$, where grain sampling and crack closure are sufficient. To date, no physically short-crack research has been conducted on this alloy for comparison to the results obtained here.

Below the value of $a_{\mathrm{o}, \text { eff,TH}}$, cracks are more dependent on local microstructural features, since they are smaller than the average microstructural dimension. In this case, cracks may grow rapidly within the grain, but may arrest once they reach a barrier such as a grain boundary. Such crack growth-arrest behavior is frequently observed in microstructurally short cracks. ${ }^{[38,39,40]}$ This might explain why failure stress is independent of the level of damage at this point.

In the case of the WMS alloy, $a_{\mathrm{o}, T H}$ and $a_{\mathrm{o}, \mathrm{eff}, T H}$ values of 45 and $30 \mu \mathrm{m}$, respectively, were reported. These transitional flaw sizes do not seem to correlate to various microstructural-length scales. Nor do the $\sigma_{T H}$ and $\sigma_{\text {eff, } T H}$ predictions seem to bound the actual data. However, the data do indicate that the fatigue failure stress can be correlated to the effective crack length. The fact that the data are not bounded by the predictions suggests that there is no short-crack effect at cracks equal to or greater than the transitional flaw size. It is possible, though, that residual stresses may have shifted the data to higher fatigue failure stress levels in Figure 10. A study of this residual stress effect is currently underway, to examine this possibility. The existence of residual stresses within the damage zone may be one explanation for this discrepancy between the model and results. The fact that this discrepancy is not observed in the 48-2-2 alloy may be due to a difference in the absolute magnitude of any residual stresses between the 48-2-2 and WMS alloys. Residual stresses would be expected to be larger in the WMS alloy, given its higher yield strength.

As can be deduced from Eq. [5], the small transitional flaw sizes in the WMS alloy are the result of a combination of high fatigue failure stress and a fatigue threshold value lower than what is typically reported for lamellar alloys. ${ }^{[4,5,6]}$ The fatigue failure stress of undamaged specimens of this alloy is $595 \mathrm{MPa}$, more than twice that of the 48-2-2 alloy, yet the $\Delta K_{T H}$ values are nearly the same (Figure 8 ). The result is that, despite the greater apparent fatigue strength of the WMS alloy, the presence of even a small flaw can reduce the strength to that of the "weaker" 48-2-2 alloy. Figure 19 shows the Kitagawa diagrams for both the 48-22 and the WMS alloys superimposed. From this figure, it can be seen that the 48-2-2 material is capable of withstanding a greater level of initial damage without a reduction in failure stress. The effect is that the failure stress in the higherstrength WMS alloy is reduced by smaller flaws and, thus, lower-impact severities. This suggests that, in considering alloy design, the advantages of higher fatigue strength may be lost when flaws are introduced into a material with a subsequently lower fatigue threshold.

In the 48-2-2 alloy, the fatigue-crack morphology was dominated by transgranular cleavage, with no signs of intergranular fracture. This is in agreement with observations by several investigators working on duplex $\gamma$-TiAl alloys of varying compositions, tested at room temperature. ${ }^{[4,5,41]}$ In the WMS alloy, the fatigue-crack-propagation mechanism could be described as mixed trans- and interlamellar fracture, with increasing amounts of interlamellar fracture at higher stress intensities. At room temperature, this fatigue fracture morphology closely resembled that in the near-indent-tip damage zone. Balsone et al., ${ }^{[4]}$ Venkataswara Rao et al., ${ }^{[6]}$ and Larsen et al. ${ }^{[42]}$ made similar observations for other lamellar $\gamma$-TiAl alloys.

\section{CONCLUSIONS}

1. For damage greater than a transitional flaw size, the fatigue failure stress of impact-damaged gamma titanium aluminide can be reasonably predicted by a thresholdbased approximation. In the 48-2-2 $\gamma$-TiAl alloy, the threshold- and effective threshold-based predictions bound the measured fatigue failure stress data. In the WMS $\gamma$-TiAl alloy, the long-crack threshold stress intensity provides a good, although somewhat conservative, approximation of the relationship between effective crack length and the measured fatigue failure stress.

2. In the 48-2-2 alloy, the fatigue failure-stress data are bounded by the effective threshold prediction (lower bound) and the threshold prediction (upper bound), suggesting that the cracks examined in this study were of such a size that they did not fully develop sufficient closure to behave as long cracks. Rather, cracks in the range from 50 to $500 \mu \mathrm{m}$ in size were observed to behave as physically short cracks. In the WMS alloy, such shortcrack behavior was not generally observed.

3. Despite a significantly higher fatigue strength in the undamaged state, the WMS alloy experiences a reduction in fatigue strength at much smaller flaw sizes than in the 48-2-2 alloy. Consequently, a threshold-based design approach would indicate that the WMS alloy would offer no inherent benefit in fatigue strength in the presence of significant damage levels $\left(a_{\mathrm{eff}}>110 \mu \mathrm{m}\right)$.

4. Significant correlations have been observed in the relationships between peak impact load and critical damage parameters in both the 48-2-2 and WMS $\gamma$-TiAl alloys. The higher yield strength of the WMS alloy results in smaller indents for the same peak impact load than for the 48-2-2 alloy. Consequently, the loads required to form an indent-tip crack of a given length will be substantially higher in the WMS alloy. The combination of these effects in the lamellar microstructure leads to an apparently greater resistance to impact damage, compared to the 482-2 alloy, for a given impact severity.

5. Fractography revealed that, in the duplex microstructure of the 48-2-2 alloy, the impact-generated damage appears as transgranular cleavage interspersed with intergranular fracture sites near the indent tip, while room-temperature fatigue proceeds by a predominantly transgranular mechanism. In the lamellar microstructure of the WMS alloy, the impact generated damage is similar to the fatigue 


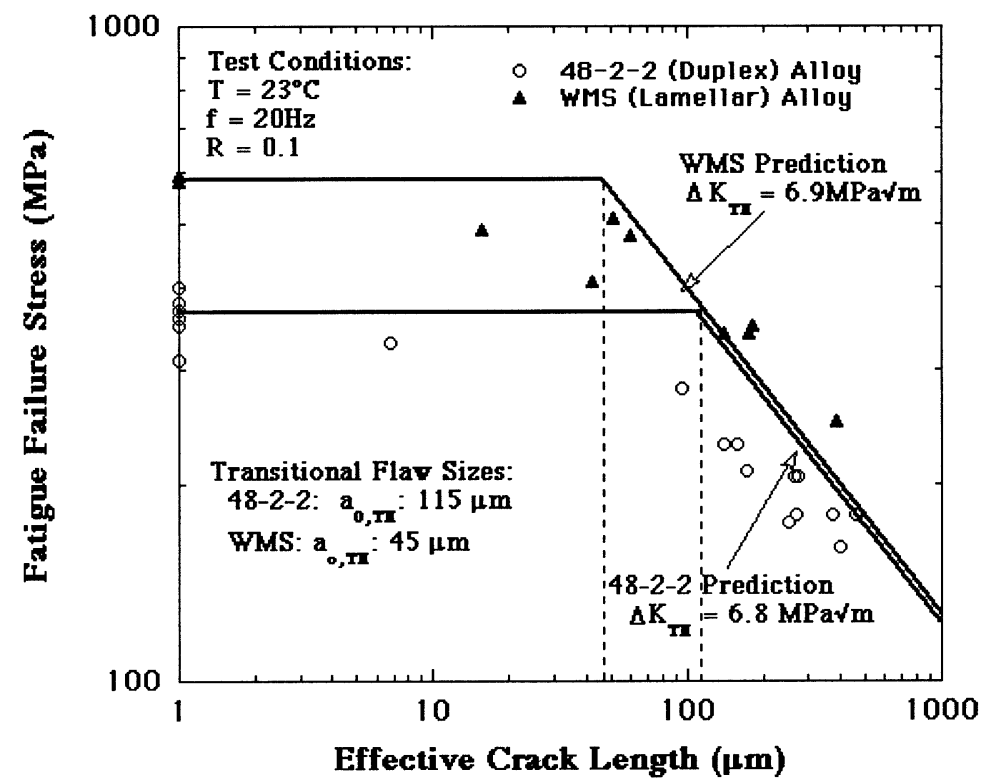

Fig. 19-Comparison of the modified Kitagawa plots of the 48-2-2 and WMS alloys. The lamellar WMS alloy is susceptible to fatigue strength reductions at smaller effective crack lengths. At severe impacts, a threshold-based approximation predicts the same fatigue strength for the two materials.

morphology of trans- and interlamellar fracture, only slightly more tortuous.

\section{ACKNOWLEDGMENTS}

The authors appreciate the assistance of several collaborators, including J.M. Larsen, A.H. Rosenberger, B.W. Worth, and G. Hartmann, Materials Directorate, Wright Patterson Air Force Base, and T.M Pollock, P.S. Steif, and M.P. Rubal, Carnegie Mellon University. This research was supported by the AFOSR through the PRET Program on Gamma Titanium Aluminide Alloys under Grant No. F49620-95-1-0359.

\section{REFERENCES}

1. C.M. Austin and T.J. Kelly: Structural Intermetallics, TMS Symp. Proc., R. Darolia, J.J. Lewandowski, C.T. Liu, P.L. Martin, D.B. Miracle, and M.V. Nathal, eds., TMS, Warrendale, PA, 1993, pp. 143-50.

2. S.C. Huang and J.C. Chesnutt: in Intermetallic Compounds: Vol. 2 , Practice, J.H. Westbrook and R.L. Fleischer, eds., John Wiley \& Sons, New York, NY, 1994, pp. 73-90.

3. J. Kumpfert, Y.-W. Kim, and D.M. Dimiduk: Mater. Sci. Eng. A, 1995, vols. 192-193, pp. 465-73.

4. S.J. Balsone, J.M. Larsen, D.C. Maxwell, and J.W. Jones: Mater. Sci. Eng. A, 1995, vols. 192-193, pp. 457-64.

5. B.D. Worth, J.M. Larsen, S.J. Balsone, and J.W. Jones: Metall. Mater. Trans. A, 1997, vol. 28A, pp. 825-35.

6. K.T. Venkataswara Rao, Y.-W. Kim, C.L. Muhlstein, and R.O. Ritchie: Mater. Sci. Eng. A, 1995, vols. 192-193, pp. 474-82.

7. B.A. Cowles: Int. J. Fract., 1996, vol. 80, pp. 147-63.

8. F.K. Haake, G.C. Salivar, E.H. Hindle, J.W. Fischer, and C.G. Annis, Jr.: Air Force Report No. WRDC-TR-89-4085, Materials Laboratory, Wright Research Development Center, WPAFB, OH, 1989.

9. J.M. Larsen, B.D. Worth, C.G. Annis, Jr., and F.K. Haake: Int. J. Fract., 1996, vol. 80, pp. 103-45.

10. T. Nicholas, J.P. Barber, and R.S. Bertke: Exp. Mech., 1980, vol. 20 (10), pp. 357-64.

11. S.C. Huang: U.S. Patent 5,076,858, 1991.

12. P.R. Bhowal, H.F. Merrick, and D.E. Larsen, Jr.: Mater. Sci. Eng. A, 1995, vols. $192-193$, pp. $685-90$.

13. C. Austin: General Electric Aircraft Engines, Cincinnati, OH, private communication, 1995
14. J. LaSalle: Allied Signal, Morristown, NJ, private communication, 1997.

15. K.S. Chart and Y.-W. Kim: Metall. Trans. A, 1993, vol. 24, pp. 113-25.

16. J.A. Collins: Failure of Materials in Mechanical Design, John Wiley \& Sons, New York, NY, 1993, pp. 379-81.

17. E.J. Dolley, N.E. Ashbaugh, and B.D. Worth: Fatigue '96: Proc. 6th Int. Fatigue Congr. G. Lütjering and H. Nowack, eds., Pergamon Press, Elmsford, NY, 1996, vol. III.

18. R.E. Peterson: Stress Concentration Factors, John Wiley \& Sons, New York, NY, 1974.

19. R.A. Smith and K.J. Miller: Int. J. Mech. Sci., 1978, vol. 20, pp. 201-06.

20. R.A. Smith and K.J. Miller: Int. J. Mech. Sci., 1977, vol. 19, pp. 11-22.

21. B.D. Worth and J.M. Larsen: Materials Directorate, Wright Patterson Air Force Base, OH, unpublished research, 1997.

22. H. Kitagawa and S. Takahashi: Proc. 2nd Int. Conf. on Mechanical Behavior of Metals, Boston, MA, American Society for Metals, Metals Park, OH, 1976, pp. 627-31.

23. M. Rubal and P.S. Steif: PRET: A University-Industry Partnership for Research and Transition of Gamma Titanium Aluminides Annual Report, Carnegie Mellon University, Pittsburgh, PA, 1997.

24. K.L. Johnson: Contact Mechanics, Cambridge University Press, Cambridge, United Kingdom, 1985.

25. A.N. Stroh: Adv. Phys., 1957, vol. 6, pp. 418-56.

26. G.E. Dieter: Mechanical Metallurgy, McGraw-Hill Book Co., New York, NY, 1986, pp. 181-82.

27. K.S. Chan and Y.-W. Kim: Metall. Trans. A, 1992, vol. 23A, pp. 1663-77.

28. T.M. Pollock, D.R. Mumm, K. Muraleedharan, and P.L. Martin: Scripta Metall. Mater., 1996, vol. 35, pp. 1311-16.

29. K.S. Chan: Metall. Trans. A, 1993, vol. 24A, pp. 569-83.

30. K.S. Chan and Y.-W. Kim: Metall. Mater. Trans. A, 1994, vol. 25A, pp. $1217-28$

31. N.J. Rogers and P. Bowen: Structural Intermetallics, TMS Symp. Proc., R. Darolia, J.J. Lewandowski, C.T. Liu, P.L. Martin, D.B. Miracle, and M.V. Nathal, eds., TMS, Warrendale, PA, 1993, pp. 231-40.

32. M. Yamaguchi: Mater. Sci. Technol., 1992, vol. 8, pp. 299-307.

33. R. Gnanamoorthy, Y. Mutoh, K. Hayashi, and Y. Mizuhara: Scripta Metall. Mater, 1995, vol. 33, pp. 907-12.

34. D.L. Davidson and J.B. Campbell: Metall. Trans. A, 1993, vol. 24A, pp. $1555-74$

35. P. Bowen, R.A. Chave, and A.W. James: Mater. Sci. Eng. A, 1995 , vols 192-193, pp. 443-56.

36. H. Shiota, K. Tokaji, and Y. Ohta: Mater. Sci. Eng. A, 1998, vol. 243, pp. 169-75.

37. K.S. Chan: JOM, 1992, vol. 44, pp. 30-38.

38. K.J. Miller: Fatigue '96: Proc. 6th Int. Fatigue Congr., G. Lütjering 
and H. Nowack, eds., Pergamon Press, Elmsford, NY, 1996, vol. I, pp. 253-64.

39. J. Lankford: Fatigue Fract. Eng. Mater. Struct., 1985, vol. 8, pp. 161-75.

40. K. Tanaka and Y. Akiniwa: Fatigue '96: Proc. 6th Int. Fatigue Congr., G. Lütjering and H. Nowack, eds., Pergamon Press, Elmsford, NY, 1996, vol. I, pp. 27-38.
41. A. Bartels, C. Koeppe, and H. Mecking: Mater. Sci. Eng. A, 1995, vols. 192-193, pp. 226-32.

42. J.M. Larsen, B.D. Worth, S.J. Balsone, A.H. Rosenberger, and J.W. Jones: Fatigue '96: Proc. 6th Int. Fatigue Congr., G. Lütjering and H. Nowack, eds., Pergamon Press, Elmsford, NY, 1996, vol. III, pp. 1719-30. 